\title{
Effect of Pursed-Lip Breathing using a Windmill Toy Model on Breathing Efficiency in Chronic Obstructive Pulmonary Disease Patients
}

\author{
Sarawut Jansang ${ }^{1}$, Parunkul Tungsukruthai ${ }^{1}$, Sorachai Srisuma ${ }^{2}$, \\ Kusuma Sriyakul ${ }^{1}$, Aungkana Krajarng ${ }^{1}$ and Somboon Kietinun ${ }^{1, *}$ \\ ${ }^{1}$ Chulabhorn International College of Medicine, Thammasat University, Pathumthani 12121, Thailand \\ ${ }^{2}$ Faculty of Medicine Siriraj Hospital, Mahidol University, Bangkok 10700, Thailand
}

('Corresponding author's e-mail: sbk9749@hotmail.com)

Received: 1 December 2020, Revised: 31 March 2021, Accepted: 1 April 2021

\begin{abstract}
Chronic obstructive pulmonary disease (COPD) is the third-highest cause of death in the world, also true in Thailand. There are various methods to treat COPD such as medication and non-drug therapies for respiratory rehabilitation. The aim of this study is to investigate the effectiveness of pursed-lip breathing (PLB) by using a windmill toy in COPD patients. The participants in this randomized controlled trial study were 60 to 75 years old. The total number of 46 participants were equally divided into 2 groups: The intervention group and the control group (23 participants each). The intervention group used breathing training through a windmill toy, whereas the control group received training in standard breathing patterns. The training was performed over sessions in 1 week. Lung function, respiratory muscle strength, and 6-minute walk test (6MWT) were recorded at baseline, and between $6-12$ weeks (follow-up). The intervention group and the control group improved significantly in lung function and muscle strength $(p<0.05)$. In addition, 6MWT in the intervention group increased significantly when compared to the control group $(p<0.05)$ at week 12. In conclusion, the PLB using a windmill toy is a new form of breathing training that is effective in promoting the strength of the muscles used for breathing, lung performance, and cardiovascular function in COPD patients.
\end{abstract}

Keywords: COPD, Pursed-lip breathing, Windmill toys, 6 minute-walk test

\section{Introduction}

Chronic obstructive pulmonary disease (COPD) is considered a major cause of morbidity and mortality worldwide [1], it more prevalent in Thailand. An observational study found that COPD is a frequent primary diagnosis of respiratory disease [1]. The development of COPD is associated with multiple factors, and the risk factors of developing COPD consist of genetic and environmental factors $[2,3]$. In COPD patients, pathological changes are detected in central airways, small airways, and alveolar spaces. The severity of COPD is well-defined by the degree of expiratory airflow limitation. The airflow obstruction is necessary for diagnosis, and forced expiratory volume in the first second (FEV1) offers a useful explanation of the severity of the pathological changes caused by COPD $[3,4]$. In addition, the most frequent symptom of patients with COPD is breathlessness related to the progression of COPD [4]. Therefore, COPD patients often find and seek medication or non-pharmacologic treatment to reduce the symptoms.

Pursed-lip breathing (PLB) is a breathing exercise that is a type of non-pharmacologic treatment. Current evidence reports that PLB helps improve pulmonary gas exchange, reduce breathing frequency (BF) and decrease hyperinflation in COPD patients [5,6]. In addition, PLB also helps decrease dyspnea and increase tidal volume in patients with moderate-to-severe level COPD [7]. For these reasons, PLB has been used regularly as a breathing technique in pulmonary rehabilitation. However, the data to support its use in patients and the development of a breathing training model are still limited [5,8,9]. The purpose of this study is to determine the effects of a new breathing training model using a windmill toy combined with PLB to promote respiratory performance, lung function, respiratory muscle strength, 6-minute walk test, and Modified Medical Research Council (MMRC) parameters. 


\section{Materials and methods}

\section{Research design}

The study design was a randomized control trial. A total number of 46 COPD patients with a mildto-moderate level of stable COPD, defined as having no exacerbations, and being aged 60 - 75 years old, were recruited from the COPD clinic in Rajavithi Hospital in Bangkok, Thailand. The inclusion criteria included normal mobility, independent self-care, and no participation in any exercise program for at least 6 months. Patients with comorbidities, such as diabetes mellitus, hypertension, congestive heart failure, tuberculosis, bronchiectasis, and intercurrent respiratory illness were excluded. All of the participants were instructed not to alter their physical activity, dietary, and lifestyle habits throughout the intervention period. The sample size was calculated by the test power of estimating, setting the significance level of 0.05 ; the test power was 0.98 based on a previous study [5]. This calculation was used when an outcome was a continuous variable, and the participants were recruited from a finite population in this study. With a projected dropout rate of $10 \%, 23$ patients per group were needed. Forty-six participants passed the inclusion criteria. They were randomized by a computer-generated list into 2 groups (23 participants each) shown in Figure 1. Forty-one patients completed the study. The reasons for 5 dropouts included loss of tracking and physical discomfort. So, there were 21 participants in the intervention group and 20 participants in the control group.

The intervention group received standard treatment with PLB practice using a windmill toy 3 sessions a week, 45 min each session (Mondays, Wednesdays and Fridays) for 12 consecutive weeks. The control group received standard treatment and routine hospital care. Both groups were evaluated by relevant parameters, including the assessment of lung function, respiratory muscles strength, 6-minute walk test (6MWT), Modified Medical Research Council (MMRC), and quality of life at baseline with follow-ups at week 6 and 12. The study was approved by the Ethics Review Committee for Research Involving Human Research Subjects, Rajavithi Hospital in Bangkok, Thailand, and it was conducted according to the Helsinki Declaration. (Trial registration number: TCTR20191009004)

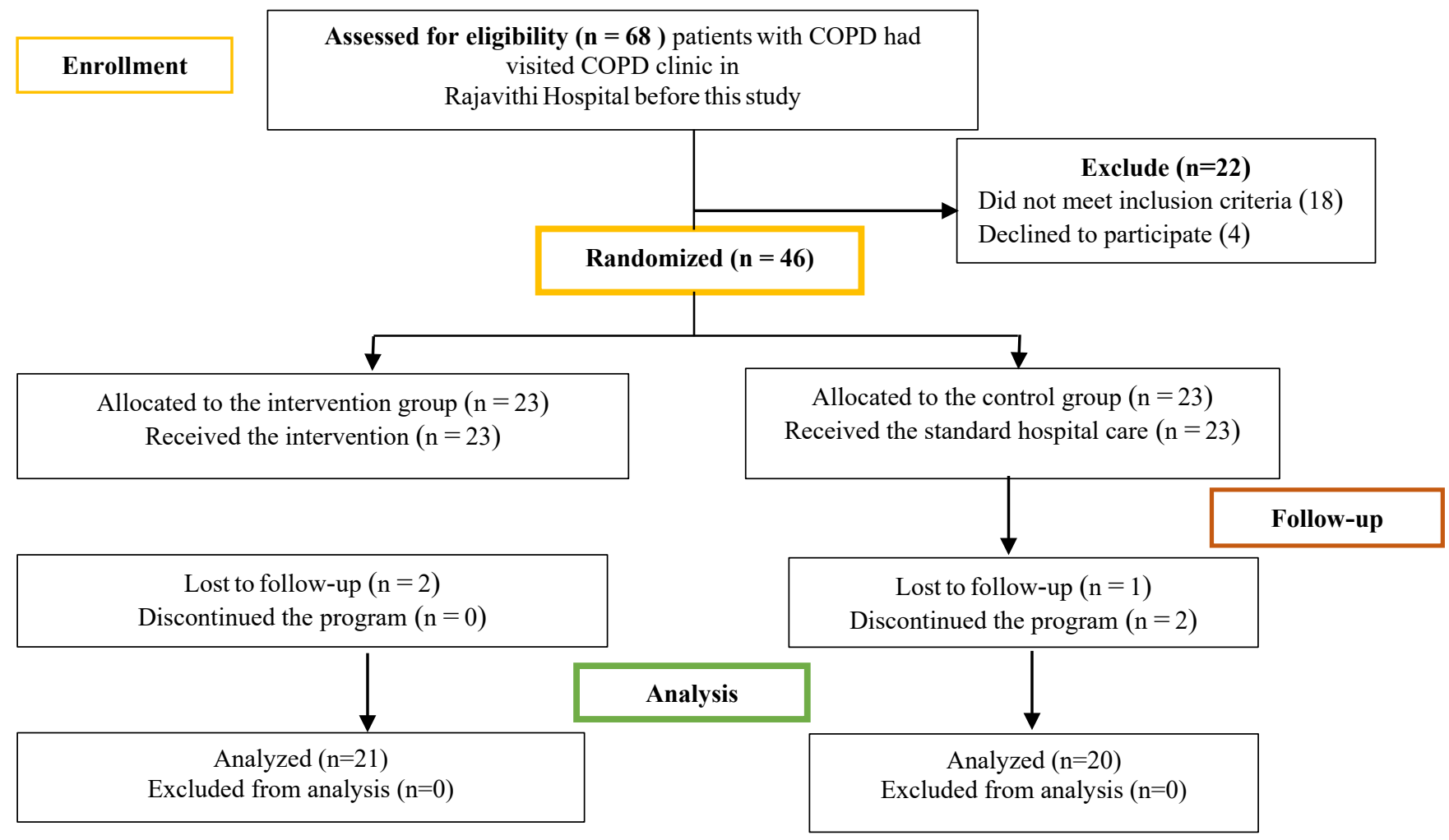

Figure 1 The flowchart of the participants showed the procedures in this study. 


\section{Research procedure \\ Planning phase}

During this phase, the breathing-training program was prepared based on the results of the assessment. The breathing training was prepared by the researcher and designed using the Thai language. It included the guidelines handout on the intervention and date of the follow-up.

\section{Implementation phase}

The intervention group

The intervention group received the pursed-lip breathing training using a windmill toy in the following steps. The researcher instructed each participant to sit in a comfortable position with both legs laid comfortably on the floor, inhale slowly through the nose, and exhale slowly through the mouth [5]. In a quiet room, the participants were instructed not to talk while practicing. The dominant hand held a toy windmill and the other hand was placed in the center of the abdomen, releasing at ease; each participant breathed slowly through the nose. As the participant inhaled, he/she was asked to count to 2, and then exhale slowly through pursed lips while blowing the windmill toy for as long as possible. As the participant inhaled, he/she was asked to count to 8 by inhalation and exhalation counted as once and then he/she was instructed to breathe normally for $1 \mathrm{~min}$. Each participant performed 10 breathing patterns in total, with 10 times equal to 1 set in the pattern experiment [5]. Each participant performed 3 sets per session, with a 3 min rest between each set, and practiced 3 sessions a week for 12 weeks.

\section{The control group}

The participants in the control group did not receive any training, but they received instructions on how to breathe and behave while participating in the research.

\section{Evaluation phase}

Modified Medical Research Council (MMRC) [8]

Evaluation of breathlessness while doing various activities. The dyspnea severity degree of the Medical Research Council Dyspnea Scale Rating, assessed by the Medical Research Council tool, measures the degree of dyspnea after performing physical activity, which can be divided into 5 different grades as follows:

Grade 1 One suffers from breathing difficulties after exercise.

Grade 2 One suffers from shortness of breath while accelerating or walking on a slight slope.

Grade 3 One has dyspnea while walking at a normal pace and would need to rest to breathe or walk more slowly than a person of the same age.

Grade 4 One requires rest to breathe after walking 100 yards or just $2-3$ min.

Grade 5 One suffers from an acute shortness of breath, even with minimal exertion, such as when getting dressed, requiring all physical activities to be stopped. It can be seen that patients suffer from a severe disease that can impair the ability to perform activities. Other physical activities are affected seriously.

\section{Lung function}

The protocol in the study followed the standards required by the American Thoracic Society (ATS) recommendations and a previous study [1]. Lung function was assessed using a calibrated computerized spirometer (spiro bank G, MIR, USA). The tests were simple spirometry and provided data for the following variables: forced vital capacity (FVC) and forced expiratory volume in $1 \mathrm{~s}$ (FEV1).

\section{Respiratory Muscle Strength}

The measurement of the maximal inspiratory pressure (MIP) and maximal expiratory pressure (MEP)was performed through a digital manometer (MicroRPM, Care Fusion, UK)[10]. The measurement had a sensitivity range of between 0 and $300 \mathrm{~cm} \mathrm{H} \mathrm{H}_{2} \mathrm{O}$ of pressure. The measurements were repeated until 3 readings were obtained with a variance of $<10 \%$. The strength of the breathing muscles refers to the force of the muscles used to contract. It depends on the length of the muscle and the correct contraction velocity. Basically, the measurement of the inhaled pressure is known as maximal inspiratory pressure (MIP or $\mathrm{PI}_{\max }$ ) whereas that of the exhaled pressure is known as maximal expiratory pressure (MEP or $\left.\mathrm{PE}_{\max }\right)$, both of which indicate the inhalation muscle strength and the exhalation muscle strength, respectively. When measuring respiratory muscle strength, volunteer cooperation is essential to obtain accurate values $[9,11]$. 


\section{6-minute walk test (6MWT)}

The 6MWT is a test that measures the distance in which a patient can quickly walk as far as possible within a $30 \mathrm{~m}$ distance in a period of $6 \mathrm{~min}$, referred to as the 6 -minute walk distance (6MWD) [1]. In this study, each participant walked for $6 \mathrm{~min}$. Oxygen consumption and the maximum $\left(\mathrm{VO}_{2} \max \right)$ were calculated as described in a previous study [1]. The 6-minute walk distance is the distance obtained from a 6-minute walk on a horizontal plane. Therefore, this test was considered as the 6-minute walk test (6MWT).

\section{Statistical analysis}

Related statistics were employed to analyze the general characteristics of the participants by using descriptive statistics. The dependent variables of each condition were expressed as mean and standard deviation; SPSS version 17 for Windows statistical software was used to analyze the data. Differences were considered significant at $p<0.05$. Student's paired t-test statistics was used to compare the mean difference of all continuous data indicators between the intervention group and the control group. The breathing training was performed using a toy windmill toy, and the repeated measure ANOVA and post hoc test were used to compare the differences at week 6 and 12 after the intervention program was implemented.

\section{Results and discussion}

Results

The general characteristics of the participants at baseline are summarized in Table 1. There were no significant differences in weight, height, and body mass index between the intervention group and the control group at baseline. Therefore, the general characteristics of both groups were similar.

Table 1 General characteristics of participants.

\begin{tabular}{|c|c|c|c|c|c|c|c|}
\hline \multirow{2}{*}{ Characteristics } & \multicolumn{3}{|c|}{ Intervention group $(n=21)$} & \multicolumn{3}{|c|}{ Control group $(n=20)$} & \multirow{2}{*}{ p-value } \\
\hline & $\mathbf{n}$ & $\%$ & Mean \pm SD & $\mathbf{n}$ & $\%$ & Mean \pm SD & \\
\hline Age (years) & & & $67.90 \pm 2.77$ & & & $66.55 \pm 3.05$ & 0.62 \\
\hline Height (cm) & & & $158.9 \pm 7.61$ & & & $158.05 \pm 8.99$ & 0.74 \\
\hline Weight (kg) & & & $63.70 \pm 9.87$ & & & $57.90 \pm 8.76$ & 0.07 \\
\hline BMI $\left(\mathrm{Kg} / \mathbf{m}^{2}\right)$ & & & $25.18 \pm 2.99$ & & & $23.14 \pm 2.68$ & $0.05^{*}$ \\
\hline \multicolumn{8}{|l|}{ Sex } \\
\hline Male & 16 & 76.19 & & 14 & 70 & & \\
\hline Female & 5 & 23.81 & & 6 & 30 & & \\
\hline \multicolumn{8}{|l|}{ GOLD COPD stage } \\
\hline I & 7 & 33.33 & & 6 & 30 & & \\
\hline II & 14 & 66.67 & & 14 & 70 & & \\
\hline \multicolumn{8}{|l|}{ III } \\
\hline \multicolumn{8}{|l|}{ IV } \\
\hline \multicolumn{8}{|l|}{ Smoking status } \\
\hline Never smokers & 10 & 47.62 & & 8 & 40 & & \\
\hline Current smokers & 3 & 14.28 & & 3 & 15 & & \\
\hline Quitters & 8 & 38.10 & & 9 & 45 & & \\
\hline
\end{tabular}

Values are expressed as Mean $\pm \mathrm{SD} . * p<0.05$ presented as compare between groups GOLD COPD = global initiative for chronic obstructive lung disease $\mathrm{BMI}=$ Body mass index 
Pursed-lip breathing using a windmill toy model did not affect cardiovascular parameters

Table 2 shows that the values of related factors variables and the Modified Medical Research Council Dyspnea Scale (mMRC) values of both groups were not different. Therefore, pursed-lip breathing with or without using a windmill toy model did not affect Modified Medical Research Council Dyspnea Scale (mMRC) parameters and related factors parameters.

Table 2 Modified Medical Research Council Dyspnea Scale (mMRC) parameters and related factors between both groups.

\begin{tabular}{|c|c|c|c|c|c|c|c|c|}
\hline \multirow{2}{*}{ Baseline } & \multicolumn{2}{|c|}{ Intervention group $(\mathrm{n}=\mathbf{2 1})$} & \multirow{2}{*}{$\mathbf{t}$} & \multirow{2}{*}{$p$-value } & \multicolumn{2}{|c|}{ Control $(n=20)$} & \multirow{2}{*}{$\mathbf{t}$} & \multirow{2}{*}{$p$-value } \\
\hline & $\begin{array}{c}\text { Pre-test } \\
\text { Mean } \pm \text { SD }\end{array}$ & $\begin{array}{c}\text { Post-test } \\
\text { Mean } \pm \text { SD }\end{array}$ & & & $\begin{array}{c}\text { Pre-test } \\
\text { Mean } \pm \text { SD }\end{array}$ & $\begin{array}{c}\text { Post-test } \\
\text { Mean } \pm \text { SD }\end{array}$ & & \\
\hline SBP & $126.80 \pm 6.80$ & $125.62 \pm 1.26$ & 2.40 & 0.06 & $129.0 \pm 5.88$ & $128.15 \pm 5.56$ & 0.91 & 0.37 \\
\hline DBP & $84.67 \pm 6.20$ & $84.00 \pm 5.50$ & 0.33 & 0.75 & $84.10 \pm 5.05$ & $83.35 \pm 3.30$ & 0.59 & 0.56 \\
\hline $\mathrm{SpO}_{2}$ & $95.24 \pm 2.36$ & $96.14 \pm 2.36$ & -1.20 & 0.26 & $94.90 \pm 2.36$ & $94.95 \pm 2.23$ & -0.07 & 0.94 \\
\hline HR & $114.00 \pm 8.83$ & $112.57 \pm 7.14$ & 0.81 & 0.43 & $112.30 \pm 8.47$ & $112.15 \pm 6.70$ & 0.08 & 0.93 \\
\hline mMRC & $1.33 \pm 0.66$ & $1.14 \pm 0.48$ & 0.94 & 0.36 & $1.10 \pm 0.72$ & $7.35 \pm 0.49$ & -1.75 & 0.09 \\
\hline
\end{tabular}

Values are expressed as Mean $\pm \mathrm{SD}$

$\mathrm{SBP}=$ systolic blood pressure

$\mathrm{DBP}=$ diastolic blood pressure

$\mathrm{SpO}_{2}=$ oxygen saturation

$\mathrm{HR}=$ heart rate

$\mathrm{mMRC}=$ Modified Medical Research Council Dyspnea Scale

Pursed-lip breathing using a windmill toy model could improve lung function, respiratory muscle strength, and cardiovascular parameters.

From Table 3, it can be seen that the intervention group had improvement in lung function, respiratory muscle strength, and 6-minute walk test parameters within the group. For example, FVC values were significantly different at week 6 and $12(p<0.05)$. In addition, in both groups, the $\mathrm{PI}_{\max }$ $\left(\mathrm{cmH}_{2} \mathrm{O}\right)$ and $\mathrm{PE}_{\max }\left(\mathrm{cmH}_{2} \mathrm{O}\right)$ were significantly different at week 6 and $12(p<0.05)$. Interestingly, the results revealed that the intervention group had significantly different 6MWD results at week 6 and 12 ( $p$ $<0.05$ ), whereas there was no significant difference of 6MWD in the control group at week 6 and 12 .

Table 3 Lung function, respiratory muscle strength, and 6-minute walk test parameters between both groups at baseline, week 6 and 12 .

\begin{tabular}{|c|c|c|c|c|c|}
\hline Parameters & $\begin{array}{c}\text { Baseline } 0 \text { week } \\
\text { Mean } \pm \text { SD } \\
\end{array}$ & $\begin{array}{c}\text { Mid-test week } 6 \\
\text { Mean } \pm \text { SD }\end{array}$ & $\begin{array}{c}\text { Post-test week } 12 \\
\text { Mean } \pm \text { SD } \\
\end{array}$ & $\mathbf{t}$ & $p$-value \\
\hline \multicolumn{6}{|l|}{ Lung function } \\
\hline \multicolumn{6}{|l|}{ FEV1 (L) } \\
\hline Intervention $(\mathrm{n}=21)$ & $1.42 \pm 0.81$ & $1.37 \pm 0.56$ & $1.73 \pm 0.65$ & -2.63 & $0.02^{*}$ \\
\hline Control $\quad(n=20)$ & $1.59 \pm 0.73$ & $1.42 \pm 0.60$ & $1.61 \pm 0.54$ & -1.72 & 0.10 \\
\hline \multicolumn{6}{|l|}{ FEV $1 \%$ predicted } \\
\hline Intervention $(\mathrm{n}=21)$ & $62.50 \pm 1.03$ & $63.30 \pm 1.00$ & $63.33 \pm 1.00$ & -5.60 & $<0.01^{* \#}$ \\
\hline Control $\quad(n=20)$ & $61.71 \pm 2.07$ & $62.44 \pm 1.04$ & $63.03 \pm 1.14$ & -2.26 & $<0.01^{*}$ \\
\hline \multicolumn{6}{|l|}{$\mathrm{FVC}(\mathrm{L})$} \\
\hline Intervention $(\mathrm{n}=21)$ & $1.63 \pm 0.78$ & $1.49 \pm 0.57$ & $1.85 \pm 0.62$ & -2.63 & $0.02^{* \#}$ \\
\hline Control $\quad(n=20)$ & $1.91 \pm 0.68$ & $1.63 \pm 0.67$ & $1.76 \pm 0.48$ & -1.72 & 0.10 \\
\hline \multicolumn{6}{|l|}{ FVC $\%$ predicted } \\
\hline Intervention $(\mathrm{n}=21)$ & $81.50 \pm 4.00$ & $84.00 \pm 3.01$ & $85.10 \pm 3.00$ & -3.51 & $<0.01^{* \#}$ \\
\hline Control $\quad(n=20)$ & $81.35 \pm 4.04$ & $81.04 \pm 4.00$ & $82.30 \pm 4.00$ & -0.74 & 0.66 \\
\hline
\end{tabular}




\begin{tabular}{|c|c|c|c|c|c|}
\hline Parameters & $\begin{array}{c}\text { Baseline } 0 \text { week } \\
\text { Mean } \pm \text { SD }\end{array}$ & $\begin{array}{c}\text { Mid-test week } 6 \\
\text { Mean } \pm \text { SD }\end{array}$ & $\begin{array}{l}\text { Post-test week } 12 \\
\text { Mean } \pm \text { SD }\end{array}$ & $\mathbf{t}$ & $p$-value \\
\hline \multicolumn{6}{|l|}{ FEV1/FVC (\%) } \\
\hline Intervention $(\mathrm{n}=21)$ & $84.06 \pm 1.84$ & $91.89 \pm 1.63$ & $93.96 \pm 6.72$ & -2.29 & $0.03^{*}$ \\
\hline Control $\quad(n=20)$ & $83.15 \pm 3.70$ & $87.09 \pm 2.66$ & $90.72 \pm 2.81$ & -1.86 & 0.09 \\
\hline \multicolumn{6}{|l|}{ FEV1/FVC (\%) predicted } \\
\hline Intervention $(\mathrm{n}=21)$ & $74.70 \pm 2.97$ & $76.36 \pm 2.01$ & $77.45 \pm 2.36$ & -2.35 & $0.04^{*}$ \\
\hline Control $\quad(n=20)$ & $75.86 \pm 1.97$ & $76.47 \pm 2.96$ & $76.58 \pm 2.86$ & -1.95 & 0.06 \\
\hline \multicolumn{6}{|l|}{ Respiratory muscle strength } \\
\hline \multicolumn{6}{|l|}{$\mathrm{PI}_{\max }\left(\mathrm{cmH}_{2} \mathrm{O}\right)$} \\
\hline Intervention $(\mathrm{n}=21)$ & $52.14 \pm 20.15$ & $56.05 \pm 24.23$ & $65.47 \pm 23.70$ & 0.01 & $0.02^{* \#}$ \\
\hline Control $\quad(n=20)$ & $56.50 \pm 26.65$ & $61.90 \pm 25.24$ & $68.65 \pm 27.68$ & 0.02 & 0.10 \\
\hline \multicolumn{6}{|l|}{$\mathrm{PI}_{\max } \%$ predicted } \\
\hline Intervention $(\mathrm{n}=21)$ & $70.24 \pm 2.00$ & $71.30 \pm 1.50$ & $73.01 \pm 1.10$ & -0.50 & $<0.01^{*}$ \\
\hline Control $\quad(n=20)$ & $71.00 \pm 2.00$ & $71.00 \pm 2.00$ & $70.50 \pm 2.00$ & 1.30 & 0.43 \\
\hline \multicolumn{6}{|l|}{$\mathrm{PE}_{\max }\left(\mathrm{cmH}_{2} \mathrm{O}\right)$} \\
\hline Intervention $(\mathrm{n}=21)$ & $54.62 \pm 18.38$ & $53.47 \pm 20.12$ & $57.23 \pm 19.90$ & 0.02 & 0.76 \\
\hline Control $\quad(n=20)$ & $49.35 \pm 19.77$ & $52.25 \pm 18.36$ & $58.00 \pm 23.91$ & 0.01 & 0.88 \\
\hline \multicolumn{6}{|l|}{$\mathrm{PE}_{\max } \%$ predicted } \\
\hline Intervention $(\mathrm{n}=21)$ & $40.00 \pm 4.20$ & $42.40 \pm 2.00$ & $45.00 \pm 1.00$ & -3.30 & 0.75 \\
\hline Control $\quad(n=20)$ & $41.15 \pm 4.00$ & $41.20 \pm 4.00$ & $42.00 \pm 3.00$ & 1.74 & 0.71 \\
\hline \multicolumn{6}{|l|}{$\begin{array}{l}\text { 6-minute walk test } \\
6 \mathrm{MWD}(\mathrm{m})\end{array}$} \\
\hline Intervention $(\mathrm{n}=21)$ & $305.95 \pm 69.81$ & $317.95 \pm 75.31$ & $329.90 \pm 71.02$ & -2.63 & $0.02^{* \#}$ \\
\hline Control $\quad(n=20)$ & $283.75 \pm 80.53$ & $287.85 \pm 84.17$ & $289.55 \pm 81.81$ & -1.72 & 0.10 \\
\hline
\end{tabular}

Values are presented as Mean \pm SD

*\# $p<0.05$ presented as Pre-test and mid test

$* p<0.05$ presented as mid test

$\mathrm{PI}_{\max }=$ Maximum inspiratory pressure

$\mathrm{PE}_{\max }=$ Maximum expiratory pressure

FEV1 $=$ Forced expiratory volume in the first second

$\mathrm{FVC}=$ Forced vital capacity

$6 \mathrm{MWD}=$ Six-minute walk distance

Furthermore, when compared between both groups in Table 4, the results reported that lung function, respiratory muscle strength, and 6-minute walk test parameter had no significant difference between both groups.

Table 4 Lung function, respiratory muscle strength, and 6-minute walk test parameters between both groups.

\begin{tabular}{|c|c|c|c|c|}
\hline \multirow[b]{2}{*}{ Parameters } & Intervention $(\mathrm{n}=\mathbf{2 1})$ & Control $(n=20)$ & \multirow[b]{2}{*}{$\mathbf{F}$} & \multirow[b]{2}{*}{$p$-value } \\
\hline & $\begin{array}{c}\text { Post-test } \\
\text { Mean } \pm \text { SD }\end{array}$ & $\begin{array}{c}\text { Post-test } \\
\text { Mean } \pm \text { SD }\end{array}$ & & \\
\hline \multicolumn{5}{|l|}{ lung function } \\
\hline FEV1 (L) & $1.73 \pm 0.65$ & $1.61 \pm 0.54$ & 0.37 & 0.55 \\
\hline FVC (L) & $1.85 \pm 0.62$ & $1.76 \pm 0.48$ & 0.04 & 0.85 \\
\hline FEV1/FVC $(\%)$ & $93.96 \pm 6.72$ & $90.72 \pm 2.81$ & 0.01 & 0.92 \\
\hline \multicolumn{5}{|c|}{ Respiratory muscle strength } \\
\hline $\mathrm{PI}_{\max }\left(\mathrm{cmH}_{2} \mathrm{O}\right)$ & $65.47 \pm 23.7$ & $68.65 \pm 27.68$ & 0.29 & 0.60 \\
\hline $\mathrm{PE}_{\max }\left(\mathrm{cmH}_{2} \mathrm{O}\right)$ & $57.23 \pm 19.9$ & $58.00 \pm 23.91$ & 0.25 & 0.62 \\
\hline \multicolumn{5}{|l|}{ 6-minute walk test } \\
\hline 6MWD $(\mathrm{m})$ & $329.90 \pm 71.02$ & $289.55 \pm 81.81$ & 4.74 & 0.06 \\
\hline
\end{tabular}

Values are presented as Mean \pm SD 


\section{Discussion}

In this study, the effects of lung function among the participants in the intervention group, who conducted pursed-lip breathing exercises by using a windmill toy, was observed to create a statistically significant increase in pulmonary function of FEV1, FEV1\% predicted, and FVC at the 0.05 level withingroup after 6 weeks of training. So, these exercises promoted lung function and respiratory endurance by increasing the values of the relevant parameters and were performed with the use of a windmill toy as a user-friendly and non-invasive breathing practice tool [5]. Pursed-lip breathing is a breathing method with a pattern to increase resistance while exhaling, causing the pressure in the trachea to increase. This could help resist the pressure generated by the pleural cavity $[12,13]$, causing the bronchi and lungs to flatten more slowly than normal effect on the air bags, resulting in a longer gas exchange rhythm $[11,13,14]$. Pursed-lip breathing training using a windmill toy to simulate the air flow rate while exhaling produces a rhythm that results in stimulating the work of the diaphragmatic muscles. Intercostal muscle and chest muscles increase the efficiency of inhaling even more after an effective exhalation [14]. When a COPD patient was trained in pursed-lip breathing by using a windmill toy correctly, the trained patient was able to breathe more effectively. Regarding the shortness of breath from exertion, previous studies on the benefits of pulmonary rehabilitation programs in patients with COPD in stages 2 - 4 were found to have respiratory conditions $[15,16]$. Difficult, reduced and valuable pulmonary function of FEV1 increased significantly at $p<0.05$, over 7 weeks in COPD patients. The intervention group who received a breathing training program using a toy windmill was found to have the average pulmonary function of FEV1, FEV1\% predicted improved after a 6-week breathing training program. The intervention group also had the mean pulmonary function of FEV1\% predicted, FVC, FVC\% predicted, and a higher average after the 12-week training program within the group than at baseline and week 6 . It was explained that the pursed-lip breathing training by using a windmill toy could improve exhalation efficiency and breathing rhythm. Increasing the volume of air flowing into the lungs as well as gas exchange in the lung tissue could be allowed a longer processing time, resulting in better lung function from the work of the chest system, causing the chest wall to move from stimulation $[5,13,17]$. Breathing the whole exhalation using a windmill toy could increase the chest volume after a maximum exhalation, which resulted in better lung function [15]. When considering the mean pulmonary function in the control group, it was found that after the 6-week program, the control group had a statistically significantly higher percentage of FEV $1 \%$ predicted [15]. The control group received instructions on breathing techniques to reduce general shortness of breath and the standard medical treatment for COPD patients. The mean values in the control group were higher after the 6-week program. These results might be possibly due to the general respiratory status of the patients who were taught breathing patterns to manage asthma [18]. When the patient learned to relieve it, he/she could follow the instructions correctly, including good breathing practices which often affected breathing efficiency, reducing shortness of breath, and motivating patients to perform better daily activities. The results were consistent with a previous study comparing Tai Chi exercise [19]. In the COPD group, there was no difference in the FEV1 or FEV1\% predicted of the intervention group compared to the control group, but the comparison within the intervention group who performed the Tai Chi exercise showed a significant difference after the intervention. In this study, COPD patients had a higher average FEV1, FVC, and FEV1\% predicted. The intervention group and control group had similar pulmonary functions because the signs and symptoms of respiratory disease are associated with the pulmonary function of the patients [16]. So, better pulmonary function in COPD patients required a minimum period of 12 weeks to practice breathing training so that physiological changes could be observed [20]. The results were consistent with a previous study which found that taiga exercise could increase lung function in patients with COPD. After the 6-week intervention, the FEV1, FVC, and FEV1\% predicted values were higher than those at baseline. Moreover, the study by Chan et al. [21] was conducted on the effect of exercise using Qigong on breathing control. At the end of the intervention program, it was found that the intervention group had a statistically significant increase in pulmonary function and there was a statistically significant increase in FEV1 after week 6 . These previous studies clearly showed that the duration of the training, exercise, or specific breathing exercises could cause physiological changes in patients with obstructive pulmonary disease, requiring training time [22-24]. In this study, a 12-week pursed-lip breathing practice using a windmill toy resulted in better pulmonary function parameters in patients with COPD. From the comparison of the strength of the respiratory muscles, it was found that the pursed-lip breathing training using a windmill toy caused an increase in inhalation muscle strength after 12 weeks of training for the higher values of $\mathrm{PI}_{\max } \%$ and $\mathrm{PI}_{\max } \%$ predicted, due to the breathing muscles stimulating specific breathing exercises as a result of the increased lung capacity corresponding to the expiratory force $[22,25,26]$. The windmill breathing is a specific inhalation pattern that stimulates the exhalation state and controls the airflow rate evenly, causing 
the inhalation process after the exhalation increases [26,27]. In addition, the diaphragm muscles work more efficiently than normal breathing conditions. The mechanism that explains the change in respiratory muscle strength is the pectoral muscles. By stimulating an increase in muscle mass, the diaphragm and the muscles that attach the outer ribs undergo structural changes, causing the inhalation muscles to also increase [27,28]. This was consistent with the study of investigating the effects of different intensity breathing exercises on heart rate and perception of fatigue [29,30]. In addition, the inhalation and chest muscles were enlarged [30]. The increased strength and performance of the breathing muscles allow the inhaled air in force inspiration to lift and expand the chest in the anterior-posterior line [29,30]. As a result of better lung function and performance, the results of 6-minute walk distance (6MWD) were significantly different within the intervention group at week 6 and 12 [24,30]. The intervention group received the pursed-lip breathing training using a windmill toy, and the results within the group at baseline and week 6 were compared and found statistically significant $p<0.05$, which was explained as a result of an increase in respiratory performance. The strength of the respiratory muscles affected the endurance of the circulatory and respiratory systems, while the 6MWD values increased distance after the 12-week breathing training. Furthermore, the results at baseline and week 6 were consistent with the study of Huang Yang $\mathrm{Wu}$ [31]. The effect of inhalation muscle training in patients with COPD found that female COPD patients had muscle strength, inhalation, and walking distance in 6 min [31]. The mechanisms of the inhalation muscle training which could improve walking performance after increased respiratory training might be a result of better respiratory strength after these breathing exercises. The strength of the respiratory muscles was associated with the feeling of breathlessness [22,23,25]. Additionally, training the breathing muscles might reduce breathing efforts, which resulted in a reduction of tiredness or a feeling of ease [21,31]. Thus, allowing the participants to walk at a higher speed without feeling too tired, this research confirmed that if the strength of the breathing muscles was stronger, it would improve the walking distance in $6 \mathrm{~min}$ [19,21,31]. Therefore, the windmill toy was a form of exercise that would benefit the participants after 12 weeks of breathing training, resulting in very positive clinical outcomes in line with previous studies. Certain equipment such as the harmonica blowing method used in pulmonary function training in patients with COPD is another lung management method that helps stretch and expand the muscles of the lungs and chest as part of pulmonary rehabilitation to improve efficiency [13,15,28,32]. Better lung and alveolar function could help reduce breathing difficulties while the participants would feel more motivated to practice breathing management. The breathing mechanism involved in blowing through the harmonica is similar to that employed when breathing with pursed lips [15]. For instance, the study conducted by Miller found that harmonica blowing for 10 min per 3 times a week for 4 weeks could help COPD patients relieve dyspnea [33]. So, in this research, the pursed-lip breathing training by using a windmill toy could increase the motivation of breathing exercises because it is a compact, easy to buy, and carry, as well as a fun and inexpensive musical instrument, and is a noninvasive, user-friendly breathing technique. It can be taken anywhere and is suitable for the elderly with COPD. Most importantly, pursed-lip breathing training by using a windmill toy could be applied as one of the COPD self-management interventions which could improve health-related quality of life and reduce physician visits and hospital use [34].

\section{Conclusions}

As a practical alternative for the non-pharmacologic treatment to reduce the symptoms of COPD, pursed-lip breathing by using a windmill toy can be applied to improve blowing patterns of these COPD patients. In the physiological values, most improved after 12 weeks due to modification of the physiological structure from long-term training and exercise. Therefore, pursed-lip breathing using a windmill toy is an effective breathing exercise intervention to improve lung function, respiratory muscle strength, and health-related quality of life in COPD patients. In essence, pursed-lip breathing is useful in improving respiratory efficiency, reducing symptoms of breath shortness in the acute phase as well as reducing the use of respiratory muscles and exercise respiratory rate in COPD patients.

\section{Acknowledgments}

This study was supported by Thammasat University Research Fund, Thailand (Contract No. TUFT 25/2562). 


\section{References}

[1] The Global Strategy for the Diagnosis, Management and Prevention of COPD, Global Initiative for Chronic Obstructive Lung Disease (GOLD) 2017, Available at: http://www.goldcopd.org, accessed March 2017.

[2] LF Cabral, TDC D'Elia, DDS Marins, WA Zin and FS Guimaraes. Pursed lip breathing improves exercise tolerance in COPD: A randomized crossover study. Eur. J. Phys. Rehabil. Med. 2015; 51, $79-88$.

[3] JB Gruenberger, J Vietri, DL Keininger and DA Mahler. Greater dyspnea is associated with lower health-related quality of life among European patients with COPD. Int. J. Chron. Obstruct. Pulmon. Dis. 2017; 12, 937-44.

[4] EA Regan, D Curran-Everett, KF Hoth, GR Washko, J Black-Shinn, CE McEvoy, NA Hanania, CA Meldrum, AM Boriek and JW Ramsdell. Worsening quality of life in COPD is associated with increasing dyspnea, reduced walking distance and baseline expiratory gas trapping. Am. J. Respir. Crit. Care Med. 2015; 191, A2839.

[5] S Jansang, T Mickleborough and D Suksom. Effects of pursed-lip breathing exercise using windmill toy on lung function and respiratory muscle strength in the elderly. J. Med. Assoc. Thai. 2016; 99, 1046-51.

[6] H Sahin, Y Varol, I Naz, N Aksel, F Tuksavul and A Ozsoz. The effect of pulmonary rehabilitation on COPD exacerbation frequency per year. Clin. Respir. J. 2018; 12, 165-74.

[7] JI Kang, DK Jeong and H Choi. The effects of breathing exercise types on respiratory muscle activity and body function in patients with mild chronic obstructive pulmonary disease. J. Phys. Ther. Sci. 2016; 28, 500-5.

[8] N Noonil, R Petsirasan and S Aekwarangkoon. Health-related quality of life and related factors in Thais with stable COPD. Walailak J. Sci. Tech. 2019; 16, 955-64.

[9] D Pinkaew, J Leelarungrayub, K Wonglangka and J Klaphajone. Effect of artificial respiratory muscle training in patients with chronic obstructive pulmonary disease. Walailak J. Sci. Tech. 2018; 15, 669-78.

[10] D Nikoletou, WD Man, N Mustfa, J Moore, G Rafferty, RL Grant, L Johnson and J Moxham. Evaluation of the effectiveness of a home-based inspiratory muscle training program in patients with chronic obstructive pulmonary disease using multiple inspiratory muscle tests. Disabil. Rehabi. 2016; 38, 250-9.

[11] NS Kim, JH Seo, MH Ko, SH Park, SW Kang and YH Won. Respiratory muscle strength in patients with chronic obstructive pulmonary disease. Ann. Rehabil Med. 2017; 41, 659-66.

[12] HD Morika, IK Sari, R Sandra and E Arman. The effect of pursed lip breathing exercise against decrease of breathing levels in chronic obstructive pulmonary disease. Int. J. Community Med. Publ. Health. 2019; 6, 4695-98.

[13] NK Sari and Suhartono. Effect of self efficacy pursed lip breathing to decrease tightness and Improved oxygen saturation in patients with chronic obstructive pulmonary disease (COPD). Int. J. Med Res. Health Sci. 2016; 5, 17-21.

[14] AF Mayer, M Karloh, KD Santos, CLD Araujo and AA Gu-lart. Effects of acute use of pursed-lips breathing during exercise in patients with COPD: A systematic review and meta-analysis. J. phys. 2018; 104, 9-17.

[15] L Ps Mendes, KS Moraes, M Hoffman, D Sr Vieira, GA Ribeiro-Samora, SM Lage, RR Britto and VF Parreira. Effects of diaphragmatic breathing with and without pursed-lips breathing in subjects with COPD. Comp. Stud. Respir. Care 2018; 64, 136-44.

[16] R Gloeckl, T Schneeberger, I Jarosch and K Kenn. Pulmonary rehabilitation and exercise training in Chronic obstructive pulmonary disease. Dtsch Arztebl Int. 2018; 115, 117-23.

[17] S Sakhaei, HE Sadagheyani, S Zinalpoor, AK Markani and H Motaarefi. The impact of pursed-lips breathing maneuver on cardiac, respiratory, and oxygenation parameters in COPD patients. Open Access Maced. J. Med. Sci. 2018; 6, 1851-6.

[18] HAV Helvoort, LM Willems, PR Dekhuijzen, HWV Hees and YF Heijdra. Respiratory constraints during activities in daily life and the impact on health status in patients with early-stage COPD: A cross-sectional study. NPJ Prim. Care Respir. Med. 2016; 26, 16054.

[19] H Ouyang. Effect of Chinese Tai chi exercise in COPD patients with moderate airflow limitation. Eur. Respir. J. 2012; 40, P3526.

[20] MA Spruit, IM Augustin, LE Vanfleteren, DJA Janssen, S Gaffron, H Jan Pennings, F Smeenk, W Pieters, J J A M van den Bergh, AJan Michels, MT J Groenen, EP A Rutten, EF M Wouters and FM 
E Franssen. Differential response to pulmonary rehabilitation in COPD: Multidimensional profiling. Eur. Respir. J. 2015; 46, 1625-35.

[21] AW Chan, A Lee, LK Suen and WW Tam. Tai chi Qigong improves lung functions and activity tolerance in COPD clients: A single blind, randomized controlled trial. Complement Ther. Med. 2011; 19, 3-11.

[22] M Beaumont, P Forget, F Couturaud and G Reychler. Effects of inspiratory muscle training in COPD patients: A systematic review and meta-analysis. Clin. Respir. J. 2018; 12, 2178-88.

[23] HY Chuang, HY Chang, YY Fang and SE Su-Er Guo. The effects of threshold inspiratory muscle training in patients with chronic obstructive pulmonary disease: A randomised experimental study. J. Clin. Nurs. 2017; 26, 4830-8.

[24] SHM Mehani. Comparative study of two different respiratory training protocols in elderly patients with chronic obstructive pulmonary disease. Clin. Interv. Aging 2017; 12, 1705-15.

[25] MM Pulsakowska, K Wytrychowski and KR Piechura. The role of inspiratory muscle training in the process of rehabilitation of patients with COPD. Adv. Exp. Med. Biol. 2016; 885, 47-51.

[26] K Klooster, NHT ten Hacken, JE Hartman, FC Sciurba, HAM Kerstjens and DJ Slebos. Determining the role of dynamic hyperinflation in patients with severe chronic obstructive pulmonary disease. Respiration 2015; 90, 306-13.

[27] B McCarthy, D Casey, D Devane, K Murphy, E Murphy and Y Lacasse. Pulmonary rehabilitation for chronic obstructive pulmonary disease. Cochrane Database Syst. Rev. 2015; 2, CD003793.

[28] AV Ovechkin, DG Sayenko, EN Ovechkina, SC Aslan, T Pitts and RJ Folz. Respiratory motor training and neuromuscular plasticity in patients with chronic obstructive pulmonary disease: A pilot study. Respir. Physiol. Neurobiol. 2016; 229, 59-64.

[29] LM Gendron, A Nyberg, D Saey, F Maltais and Y Lacasse. Active mind-body movement therapies as an adjunct to or in comparison with pulmonary rehabilitation for people with chronic obstructive pulmonary disease. Cochrane Database Syst. Rev. 2018; 10, CD012290.

[30] H Duan, P Li, Z Wang, H Chen, T Wang, W Wu and X Liu. Effect of 12-week pulmonary rehabilitation on cognitive function in patients with stable chronic obstructive pulmonary disease: Study protocol for a single-center randomised controlled trial. BMJ Open 2020; 10, e037307.

[31] CH Huang, GG Yang, YT Wu and CW Lee. Comparison of inspiratory muscle strength training effects between older subjects with and without chronic obstructive pulmonary disease. J. Fla. Med. Assoc. 2011; 110, 518-26.

[32] DM Cardoso, R Gass, G Sbruzzi, DC Berton and MM Knorst. Effect of the expiratory positive airway pressure on dynamic hyperinflation and exercise capacity in patients with COPD: A metaanalysis. Sci. Rep. 2020; 10, 13292.

[33] SS Miller. A Comparison of COPD patients' quality of life using the harmonica as a means of pulmonary rehabilitation, Available at: http://hdl.handle.net/10755 /201965, accessed January 2012.

[34] SB Bensten, E Langeland and AL Holm. Evaluation of self-management interventions for chronic obstructive pulmonary disease. J. Nurs. Manag. 2012; 20, 802-13. 